\title{
8. The information systems discipline in Tasmania
}

\author{
Gail Ridley \\ School of Accounting and Corporate Governance \\ University of Tasmania
}

\begin{abstract}
This chapter reports on a study that examined the information systems (IS) discipline in Tasmania. The study draws on a theoretical framework reported earlier in this volume. The study aimed to characterise IS at the University of Tasmania, as well as to investigate the relationship between the impact of local contingencies on the IS discipline and its degree of professionalism, within the Tasmanian context. Data were collected through a qualitative survey with seven influential academics associated with the discipline at the university, and from statistical sources. The findings suggest that an inverse relationship exists between the impact of local factors and the degree of professionalism in this setting. A surprising finding was that the relationship found varied for research and teaching issues. As the structural location of the School of Information Systems changed from 2008, two different perspectives on the relationship between IS and computing at the University of Tasmania are presented, and vignettes are provided of two academics who have had an influence on IS in the past. The forthcoming structural relocation of IS at the university is a demonstration of the degree of change experienced in the discipline.
\end{abstract}

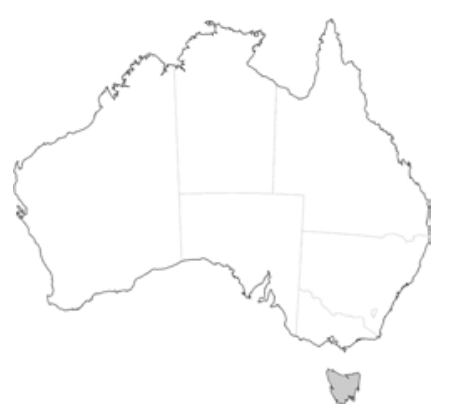

Figure 8.1 Location of Tasmania within Australia 


\section{Introduction}

The current chapter reports on a study of the state of the IS discipline in the only university in Tasmania, and draws on a theoretical framework outlined in an earlier chapter in this volume. The theoretical construct that guides this investigation will not be restated. This study is one of a series of similar studies undertaken in each Australian state and the Australian Capital Territory, and reported on elsewhere in this volume. This chapter extends on an earlier publication, published in the Australian Journal of Information Systems (Ridley 2006).

Tasmania is a unique state in Australia as it has only a single university, which is one of the oldest universities in the country. The University of Tasmania (UTAS) was established in 1890 in Hobart. In 1991, the university merged with the Tasmanian State Institute of Technology in Launceston, forming a second campus, in the north of the state. Then in 1995, the North-West Centre was opened in Burnie, which was renamed the Cradle Coast Campus in 2005. In 2008, the integration of the UTAS and the Australian Maritime College took place. Although the UTAS has just more than 12000 students, it offers one of the widest selections of courses in Australia (University of Tasmania 2007), including 15 within the discipline of IS.

\section{Aims of the study}

This study aims to characterise the state of the IS academic discipline in the UTAS, and also contribute to a better understanding of the same discipline in universities throughout Australia. Consequently, the data gathered for the study will be analysed at three levels. Table 8.1 sets out the three levels.

\section{Table 8.1 Three levels of analysis discussed in the study}

\begin{tabular}{l|l|l}
\hline $\begin{array}{l}\text { Covered in } \\
\text { this paper }\end{array}$ & Level & Scope \\
\hline & 1 & Descriptive analysis using quantitative and qualitative sources \\
\hline & 2 & $\begin{array}{l}\text { Examines whether an inverse relationship exists between the impact of local } \\
\text { contingencies on the discipline and the degree of professionalism }\end{array}$ \\
\hline & 3 & Cross-case analysis drawing on theoretical framework \\
\hline
\end{tabular}

The first level of analysis will be reported in this current chapter and provides a descriptive examination of IS at the UTAS from qualitative and quantitative sources. The second level of analysis will also be reported in this chapter, and aims to examine in the Tasmanian IS academic context the postulation contained within the theoretical framework that an inverse relationship exists between the impact of local contingencies on a discipline and its degree of professionalism.

At the third level of analysis, some of the data gathered for the current study will be utilised for a cross-case analysis, and reported elsewhere. The cross-case analysis will draw on the remainder of the theoretical framework, which contends that a discipline will establish over time with the development of mechanisms 
of control and a core body of knowledge. This component of the theoretical framework cannot be investigated in a single case, as cross-regional analysis is required on such issues as key IS research and teaching topics, and whether a unique symbol set exists for the discipline. Moreover, some Australian longitudinal data will be needed at this third level.

Consistent with the content of the other state reports, the following issues have been examined within Tasmanian IS academia:

- the extent to which IS is/was impacted on by local contingencies

- the extent to which IS is/was identified as a separate field at the university

- the distinctive features of the IS curriculum at the university

- the distinctive features of IS research at the university

- the perception of the key people in the region who have had an impact on IS at the UTAS.

Changes to the structural placement of the School of Information Systems at the UTAS were first proposed in 2006 - for implementation in 2008 - and involved a closer relationship between the IS and computing disciplines. Consequently, another aim of this chapter was to consider different perspectives of the relationship between the two disciplines, as provided by a senior academic from each discipline at the UTAS. A further aim of the chapter was to present vignettes of two academics who were influential on the IS discipline at the university in past years.

\section{Background}

The reader is referred to an extensive review of the literature on the development of disciplines that has been provided in the earlier framework chapter of this volume. The methodology used for the current study is presented next.

\section{Methodology}

The Tasmanian case study was based on a detailed case-study protocol developed by the Queensland study team members.

Before the two schools merged, an open-ended questionnaire was e-mailed as an attachment to the participants after piloting. Where a response had not arrived within the time frame indicated for the return of the questionnaire, contact was again made with the academic, either in person or by e-mail, to encourage them to respond.

Eight academics who were currently closely involved with IS at the UTAS, or who had been in the past, were approached to participate in the survey. Of these, five were currently involved in either IS teaching or research, or both, at the university in Information Systems. Of the remaining three academics, two were working as IS academics outside Tasmania, while the third was employed 
in an allied discipline elsewhere at the UTAS at the time the data were collected. Of the participants, four had been employed as a head of school or in a more senior position. The three participants no longer working with IS academics at the UTAS were known internationally in IS or an allied discipline. Although the author of this chapter was also a former member of the School of Information Systems at the UTAS, her views were not included in the data collection and care was taken to try to exclude them from the analysis. This was done by having another person trained in IS research methods categorise the data after they had been stripped of identifying characteristics, and, where the classification differed, agreement was reached after discussion.

The survey method was used as some of the participants were located in other states or nations. An interview was, however, conducted with one of the participants. Some of the responses took participants up to two hours to complete. Consequently, the survey and interview captured broad perceptions of the state of IS at the UTAS, as well as points of differentiation and distinctive characteristics of IS at that university. Existing statistical and archival material were also collated to supplement the data obtained from the participants, and to facilitate some degree of triangulation. After the chapter was written, the original participants were invited to comment on it. Five participants took up this invitation.

A thematic analysis process was followed, allowing the integration of the qualitative data collected from participants and the quantitative data collated from other sources (Dixon-Woods et al. 2005). Although thematic analysis can be data driven, in this study the themes were driven by those in the theoretical framework referred to earlier. The discussion reported in the findings section below was 'weighted towards themes that appear to have a high level of explanatory value', rather than reflecting how frequently the themes were reported (Dixon-Woods et al. 2005:47).

The text relating to each question was examined for themes arising from the framework. The themes, and issues arising from the themes, have been presented below, grouped into the five major categories set out earlier. Statistical and archival data have been incorporated into the discussion relating to the themes, where relevant. The discussion of the themes in the section below presents the findings of the descriptive examination of IS at the UTAS from qualitative and quantitative sources, and forms the first level of analysis for this study.

After discussion of the themes, two tables were prepared to analyse the data at the second level. The second-level analysis examines whether an inverse relationship exists between the impact of local contingencies on a discipline and its degree of professionalism, in the Tasmanian IS academic context. In order to do this, the impact of local contingencies on IS teaching and research at the UTAS, and its degree of professionalism, were each independently categorised 
by two researchers as high, medium or low. Consistent with the previous framework chapter, professionalism was regarded as having high task certainty, routinisation of activities and a clear division of labour. Where a discipline was not highly professionalised, however, the control of work process would be decentralised, with limited routinisation of tasks (Whitley 1984).

In addition to the data collected in the manner described above, a senior academic from the School of Information Systems at UTAS provided updated information in mid-2007 on the school's research and teaching directions. Also, two senior academics were approached to comment on the merger of the schools of IS and Computing, and its implications, from their perspective. Two vignettes on senior academics, linked to IS at the UTAS in the past, were also solicited and included in this chapter.

\section{Analysis and findings: level one}

This section first presents demographic characteristics of the respondents, as well as a discussion of the administrative placement of the School of Information Systems and the size of the IS presence at the UTAS. The findings and discussion follow, relating to the five common themes listed earlier.

\section{Respondent characteristics and IS administrative placement and size}

Responses were received from all but one of the people contacted. The replies were far from cursory and enabled personalised, reflective and deep responses, beyond what was likely to be obtained if all the data had been collected via interview. The demographic characteristics of respondents appear in Table 8.2.

Table 8.2 Demographic details of survey participants

\begin{tabular}{l|c|c|c|c}
\hline Gender & Male & Female & & \\
\hline PhD held & 5 & 2 & & \\
\hline & Yes & No & & \\
\hline Discipline of PhD & 5 & 2 & & \\
\hline & IS & CS $^{\text {a }}$ & & \\
\hline Age (estimated) & $40-50$ & 2 & & \\
\hline & 2 & $51-60$ & $61-70$ & 2 \\
\hline Current position & Professor & Associate professor & Senior lecturer & Lecturer \\
\hline & 3 & 2 & 1 & 1 \\
\hline
\end{tabular}

${ }^{\mathrm{a}} \mathrm{CS}=$ computer science

Although the UTAS introduced a major in information technology (IT) about 1987, it was only about 1992 that a recognisable IS program was introduced. Before January 1997, the academic discipline of IS was co-located with computing in the Department of Computer Science, in the Faculty of Science and Engineering. The School of Information Systems was formed in January 1997, 
and was located administratively within the Faculty of Commerce (from 2006, the Faculty of Business). The School of Information Systems is one of four schools located within the faculty, the others being Management, Accounting and Corporate Governance, and Economics and Finance. In 2005, the school delivered IS units at six locations: Hobart, Launceston and the Cradle Coast Campus in Tasmania, Shanghai and Fuzhou in China and Jakarta in Indonesia.

In 2005, 17 staff members were employed either full-time or part-time, and based in the School of Information Systems. Of these, 13 were academic (one part-time), while two undertook research positions. All but 11 academic staff members were based in Hobart, two were located in Launceston and no staff member was based permanently at the Cradle Coast Campus, or in Shanghai, Fuzhou or Jakarta. Table 8.3 sets out the staff and teaching locations.

In semester two 2005, the school had 1010 students based in the six locations, which represented about 800 equivalent full-time student units (EFTSU) in total. Eight undergraduate programs existed at that time, four graduate course-work programs and a PhD program. Further course-work graduate programs were introduced in 2006. The programs on offer at the School of Information Systems as of the end of 2005, and as of mid-2007, have been set out in Appendix 1.

Table 8.3 Summary of staffing and teaching centres in 2005

\begin{tabular}{l|c|c|c|c}
\hline UTAS teaching locations & Hobart & Launceston & Cradle Coast & $\begin{array}{c}\text { Shanghai, Fuzhou, } \\
\text { Jakarta }\end{array}$ \\
\hline Academic staff & 11 & 2 & 0 & 0 \\
\hline General staff & 4 & 0 & 0 & 0 \\
\hline
\end{tabular}

It was first proposed in 2006 that the School of Information Systems should merge with the School of Computing from the Faculty of Science, Engineering and Technology. Planning for the merger started in 2007, with the new merged school operating from the start of 2008.

\section{Impact of local contingencies}

The next section sets out the extent to which IS was believed by the survey participants to be impacted on by local contingencies at the UTAS.

\section{Curriculum and teaching issues}

The multi-campus operation of the university within Tasmania, and the associated delivery of IS in those three centres, was seen to have come about, at least in part, by the influence of Tasmanian politicians. A participant referred to the difficulty in adjusting the staff profile to student demand, which varied by campus, and balancing this issue and others due to funding pressures.

Course advisory committees were another way that local perspectives had impacted on the courses in the past. These committees, which met irregularly, were established for the IS programs when the School of Information Systems 
began in 1997. Although course advisory committees had provided feedback on the curriculum of the Bachelor of Information Systems and Honours programs, they did not influence their design or development significantly. The Master of Information Systems (MIS) program was, however, designed and introduced as a response to demand for graduate professional development in IS from the Tasmanian state government. The MIS Course Advisory Committee played a significant role in the curriculum and delivery modes for that program between 1997 and 1999. In contrast, the Bachelor of Information Systems degree curriculum was influenced strongly by the broader issues of national published curricula, which included IS'95 (Longnecker et al. 1995) and the Information Resources Management Association (IRMA 1996).

Another study participant commented on a need for greater involvement of course advisory committees in more recent years to update the curriculum, but noted the introduction of logistics to the undergraduate curriculum in the past few years as a response to external demand. Two other respondents saw little evidence of the school's curriculum responding to local external factors. One of these participants noted, however, that the school had responded to international demands in a considerable way, making reference to how the curriculum had changed to accommodate Department of Immigration and Multicultural and Indigenous Affairs (DIMIA) requirements and those of the international market.

The nature of the IS programs varied considerably, depending on location. Traditionally, the majority of the school's students were located in Hobart, while Launceston had the second-largest proportion of students. Few students were based in Burnie, and it has not been possible to complete an undergraduate IS degree there. Since the school started to deliver IS into Shanghai, however, the distribution of students by campus changed dramatically. For example, as of November 2005, 75 per cent of the total EFTSU of 800 (1010 students) of the School of Information Systems were international students. Although some of the international students studied onshore at Tasmanian campuses, 61 per cent of the school's total EFTSU were enrolled offshore in China. A total of 59 per cent of the school's EFTSU were enrolled in a Bachelor of Information Systems degree in Shanghai, while 38 per cent were enrolled in a range of programs in Hobart, which are listed in Appendix 8.1. All graduate programs were delivered onshore, although for the first time in 2006 students from the first cohort to graduate with a UTAS undergraduate degree from Shanghai undertook an IS course-work Masters degree based in Hobart.

In recent years, the teaching has become more centralised into the Hobart campus. A limited number of units were offered at Launceston, and fewer were available at the Cradle Coast Campus. Increased use has been made of video-conferencing and other electronic means of delivery into Launceston and the Cradle Coast Campus. The teaching focus within an individual unit did not, however, vary 
by campus. No Honours or Masters programs were offered in centres outside Hobart, although they had been offered in Launceston in past years.

Since the School of Information Systems was first established, emphasis had been placed on consistent teaching across the campuses, and moderation of assessment across the multiple campuses in Tasmania. This aim was achieved by using a single point of course development for each unit, while employing teaching teams that operated across all campuses. Moreover, either single points of assessment were utilised for each unit or team marking was used that spanned the centres. Although some divergence in delivery modes and assessment occurred in Shanghai and Fuzhou since the IS programs were introduced there in 2003, very similar content had been retained in all units across all centres.

\section{Research issues}

The research program has not been controlled centrally within the school, resulting in some variation in the nature of the research conducted within Tasmania. For example, there were few common topics between researchers in recent years other than an interest in e-commerce. This interest was seen by one participant to be related to the era rather than a consciously adopted focus. Another participant made reference to an early emphasis on e-commerce in the School of Information Systems, from a curriculum and a research perspective. The same participant identified the establishment of the Tasmanian Electronic Commerce Centre, originally located within the School of Information Systems in Hobart, as a driver for this emphasis. A comment was made about a perceived need to focus on fewer research areas.

A decision to emphasise qualitative research methods taken in the past was still apparent in 2005, with most Honours and $\mathrm{PhD}$ projects using qualitative techniques. In the same year, however, the school in the centres outside Tasmania undertook no research. One participant commented that the UTAS did not have a distinct research identity, while several references were made to the need for a greater research culture in the school. This influence and others were seen to act against the development of research collegiality, which also hindered research. Many staff members were early career researchers who were still working towards completing their PhD or gaining expertise and recognition within their research area. Other participants referred to the lack of qualified supervisors available in the school, and the situation in which one or two staff members supervised relatively large numbers of PhD students - in particular, Dr Paul Turner. The appointment of staff members who had studied within the school led to an emphasis on one research method, which was seen as problematic by one participant.

Another local contingency to act on research undertaken by the School of Information Systems was the funding obtained by Senator Brian Harradine and 
used in part to set up the Telstra Broadband Laboratory. The laboratory became the focus of some of the school's research for a period. One participant referred to the proposal to amalgamate all faculty research in a single school, while another participant pointed to the role of the Faculty of Business in identifying research areas. The appointment of the Woolworths Chair in Information Systems in 2004 was described as a consequence of political pressure on the state government to relax shop trading hours.

Other evidence was provided for the way the nature of research conducted in the school had been influenced by local contingencies. One participant pointed to the advantages of researching in a state capital with a small population. Several references were made to the range of local industry contacts that the school drew on, with many student projects based within the community. The small size of Tasmania had resulted in federal and state government agencies being relatively easy to access. In the past, both tiers of government were supportive of research that used their organisations for data collection. As a consequence, the School of Information Systems focused on applied projects with relevance to the industry and government bodies that participated in such research. As another example, the limited number of large private-sector organisations in Tasmania had directed research efforts to the small to medium-sized enterprises (SMEs) and public-sector environments. The minimal extent of manufacturing carried out in the state had also acted to limit research undertaken through the school in this setting.

Finally, it was claimed that IT was more likely to be dealt with by accountants in the state rather than by senior IT staff, while greater use of consultants and outsourcing in Tasmania was reported. All three of the last characteristics were seen to impact on research undertaken in the School of Information Systems.

\section{Comparison with other disciplines}

A degree of divergence was seen in the views of participants on whether IS was affected by local factors to a greater or lesser degree than for other disciplines at the UTAS. Several participants saw IS being affected by local factors to a similar extent as the other disciplines within the university, while another commented that little attention was paid to all computing-related disciplines.

Two participants commented that in comparison with other disciplines at the UTAS, the volatility of the IS discipline meant that there was a greater need to maintain the currency of the curriculum and to give students access to current technology, which had resource implications.

\section{IS as a separate field}

This section considers the extent to which IS has been identified as a separate field at the UTAS. 


\section{The extent to which IS has a separate identity}

The introduction of IS within the Department of Computer Science at the UTAS was an initiative of Dr Michael Rees. After his departure, Dr (later Professor) Chris Keen took over the role of IS advocate. Since then IS has had a separate identity in the Faculty of Business, and communication with Computing has been reduced, which, according to one participant, has been to the loss of both schools.

Although IS at the UTAS was seen by the participants to have a separate identity, this characteristic had taken more than 10 years to achieve. Information systems has been acknowledged formally as a single field of study and research within the university since January 1997, with the formation of the School of Information Systems. From about 1994, IS was associated mainly with a group operating within the Department of Computer Science at the Hobart campus. Towards the end of that year, IS was identified formally as a distinct teaching field within the Department of Computer Science. There was, however, also a smaller IS teaching and research group within the Department of Applied Computing at Launceston. Referring to the time in which IS was establishing itself at the UTAS, a participant who had been associated with the school for many years commented that most discipline areas at the university were unclear about the nature of the field. Another participant now employed outside Tasmania saw relevance as the key for survival where confusion existed about the nature of the discipline, and where opportunities and the professional community were small.

\section{Distinguishing IS from business and computer science}

In 1996, extensive discussion occurred between the staff of the proposed School of Information Systems and what were at that time the departments of Computer Science and Applied Computing. A participant reported that teaching and research topics were readily grouped into those suggested at that time by the Australian Computer Society (ACS). The topics were divided into the technical aspects of computer programming, software engineering, networking, computer systems engineering and computer science, and for IS, the business and social aspects of the application of information and communications technology (ICT). The same distinction largely continued until 2008.

In general, until recently, the participants saw computing and IS as having different perspectives, with limited communication between the two disciplines; however, they saw less to distinguish IS from business, with IS being concerned with the management of IT and not as broadly based as business. The IS units offered limited technical content, which was found in the School of Computing. One participant saw pressure on computing schools to shift towards IS teaching areas, in response to falling student enrolments. As evidence of this claim, 
database management has been introduced by the School of Computing in some units in recent years, delivered by their own staff members. One participant saw the demise of service teaching to be partly responsible for this last development.

One participant pointed to current pressures that act against IS groups continuing as independent schools at the UTAS and elsewhere, foreshadowing the amalgamation of IS with computing at the UTAS in early 2008.

\section{Comparative status of IS academics}

Four participants believed that IS academics had a similar status to business and computing academics at the UTAS. A comment was made that while IS and business academics had the same status, academics from schools situated within the Faculty of Science and Technology had higher status, due to the better research profile in that faculty at the university - the School of Computing was located in the Faculty of Science and Technology at the UTAS. Another participant, however, compared the size of the Schools of Computing and Information Systems when considering the status of each. The Schools of Computing and Information Systems had similar EFTSU numbers as of late 2005, with the former being the third-largest school and the latter the fourth-largest school in the university at that time. Finally, another participant considered IS academics to have a lower status than their colleagues in computing or management at the UTAS.

\section{Comparative use of terminology}

Most of the participants who responded to this question considered that IS terminology used at the UTAS would be broadly familiar to their business and computing colleagues. One person, however, believed that there was relatively little understanding of the conceptual base of IS among many staff in business. Another noted the limited contact between IS and computing staff before 2008, which, it was assumed, would make it difficult to assess the commonality in the terminology used by each group.

\section{Features of IS curriculum and teaching}

In the next section, the IS curriculum and teaching at the UTAS will be characterised.

\section{The role of IS service teaching}

As the School of Information Systems did not differentiate strongly between service and core teaching, there was less service teaching undertaken than in some other universities. For example, the same undergraduate IS units are offered within the Bachelor of Information Systems degree and its associated combined degrees as are available across all other degrees offered by the university. A 
number of students undertake IS units within business, economics, science, computing, arts and geomatics degrees. Information systems degrees accounted for approximately 80 per cent of the teaching load while other degrees account for approximately 20 per cent. What is regarded commonly as service teaching occurs only with the provision of two IS units within the geomatics degree.

A pressure that acts against service teaching occurring is the motivation of other disciplines to retain funding and, according to one participant, the limited value placed on the philosophies of other schools. There was no core IS unit in the university's MBA program, which was seen as worthy of note.

\section{Distinctive themes and teaching styles}

A focus on management and strategy was identified in the IS teaching at the UTAS, with less emphasis on technical issues. This focus incorporated the major themes of project management, data modelling, data management and electronic commerce. Oracle database management is taught to Oracle-certification level. Oracle is taught because of its use in the Tasmanian government-a major employer of IS graduates. At the undergraduate level there are three majors: systems development, e-business and management of IS. The approach taken in earlier years at the school, when professional development was integrated into the undergraduate teaching program, was seen as distinctive. This focus had, however, waned more recently. The business logistics unit taught at undergraduate level was also identified as distinctive. One participant commented that the IS teaching program at the UTAS was not significantly different from the range of topics taught elsewhere in Australia.

Relatively few suggestions were made regarding distinctive features of IS teaching at the UTAS, while one participant stated that no features of the teaching program were distinctive. Mention was made, however, of the significant use of discussion workshops and case studies in the school. Reference was made also to the individual attention provided to students, which was perceived to foster their confidence and encourage them to continue on to higher degrees. Another participant commented on the high quality of the flexible online support that was provided to support the teaching program.

\section{Distinctive tools, techniques and technologies}

Although one participant commented that there were no tools, techniques or technologies that were distinctive in the IS teaching at the UTAS, some techniques associated with teaching delivery were identified as distinctive, including what was perceived as an effective combination of face-to-face and online delivery. Reference was made to the sequential delivery style for units from Year One to Three, designed to facilitate the progression of student responsibility for their own learning. For example, in the later semesters of a degree many units 
de-emphasised lectures to communicate knowledge, and placed more reliance on online resources with consolidation of the knowledge in workshops.

\section{Other teaching issues}

A range of teaching-related issues was raised by the academics as important. Declining local enrolments was one such issue, and the associated very high international load was another. One participant linked declining enrolments to a perceived falling interest from young people in IT, and a negative image for the discipline. Reference was made also to the associated unbalanced distribution of the teaching program across six centres, particularly as the majority of the school's students were located in China as of late 2005.

Several participants commented on the need to monitor whether the programs delivered by the School of Information Systems remained relevant to current needs and trends. In particular, several participants remarked on the need to ensure that the school's IS graduates had access to the technical skills expected from employers. It was noted that in past years the school's staff had included people with expertise in advanced databases and networking, but more management-oriented staff had been appointed since that time. More recently, an attempt had been made to correct this perceived imbalance through recruitment of staff with specialist technical skills. One participant no longer working in the discipline suggested the school should consider a greater degree of reintegration with computer science-which later took place.

\section{Changes planned for teaching and curriculum in the next three years}

Finally, few changes to the nature of the IS teaching or the curriculum in the coming three years were identified; however, the new Masters programs introduced from 2006 were raised: ME-Business, ME-Business with a Specialisation and M-Logistics.

One participant foreshadowed a move for the school in future years away from IT and systems development to operations management and a business process focus that would require greater coverage of business-analysis methodologies. This change was regarded as a necessary response to falling enrolments.

\section{Features of IS research}

The features of IS research at the UTAS are discussed below.

\section{Research output and funding}

Although there was general recognition that the research output of school staff was relatively low, several participants identified that the contribution was skewed. The majority of publications were in national and international refereed conferences, with a limited number of quality journal publications. One 
participant no longer working at the UTAS saw an opportunity for researchers to target high-quality conferences and journals in order to obtain quality feedback. For this to happen it was identified that broadly accepted academic leadership and a unifying research culture would be required, enabling the development of research groups and the emergence of research strengths for the school.

One participant believed that in the late 1990s the school's research focused on rigorous interpretive research methodologies. At that time, it produced a series of quality $\mathrm{PhD}$ theses, evidenced by comments from staff from other schools in Australia and the later success of some of those PhD graduates.

The school did not have a strong history of attracting Australian Research Council (ARC) Discovery funding. The majority of the research funding obtained by IS in recent years has come from external, national competitive grants from the Smart Internet and Sustainable Tourism collaborative research centres and ARC Linkage grants. A limited number of the school's staff was involved in attracting these research funds. More recently, one staff member in particular had attracted considerable industry funding to the school, particularly in the area of e-health.

Small internal research grants have been made available by the Faculty of Business, while the university-wide Institutional Research Grants Scheme is designed to prepare staff for the future submission of ARC grants.

\section{Balance between research and teaching and incentives for each}

As teaching loads were high, participants perceived that pressure existed to push the balance away from research towards teaching. Some staff had a teaching and administrative load only, while several staff members had a 75-85 per cent research load. The majority of staff members were, however, expected to undertake teaching, research and administration.

Some participants perceived greater recognition was given for good teaching than for research at the university through processes such as teaching merit certificates, teaching development grants and evaluation of teaching and learning. At a faculty level, however, there has been a recent attempt to redress this through the introduction of research awards. Faculty funding is available to assist staff to travel to conferences, which needs to be combined with school professional development funding. A faculty scheme of seed funding to encourage a range of different forms of research was introduced several years ago. A comment was made that incentives for the conduct of quality research could be defined and implemented better. For example, the same participant perceived that highly productive research staff did not receive recognition or incentives through the distribution of research quantum income. The same participant considered that the Department of Education, Science and Training (DEST) point 
system was ineffective in challenging staff to undertake better research. The new approach of the federal government to research outcomes in Australian universities could, however, redress this situation.

Research and teaching targets for individual staff are set within the compulsory performance management scheme implemented at the UTAS. Promotion is linked to good research outcomes and, more recently, an alternative route to promotion has been introduced through the demonstration of quality teaching.

\section{Conference attendance}

It was believed that active researchers in the school would attend on average one to two conferences a year. In the past, the Australasian Conference of Information Systems (ACIS) has been popular with staff and research students because it provides researchers with opportunities to network. One participant, however, commented that attendance at ACIS by school staff had declined in recent years. ICIS, ECIS, HICSS, GITMA, IRMA and other topic-specific national or regional conferences have been attended occasionally by at least one staff member, while health care and security conferences have been popular.

\section{Changes planned for IS research in the next three years}

Finally, few comments were made on changes planned for research in the School of Information Systems in coming years. Associated with the relatively recent appointment of a Woolworths Chair in Information Systems at the school, several participants referred to a new focus on IT governance and business process management. This move was seen as having potential to benefit the school, and several comments related to a desire for the emergence of a collegial research culture. While a senior participant foreshadowed a limited research group culture for the future, based on the belief that it was not possible to 'bureaucratise IS research', another saw progress of the IS discipline at the UTAS as being linked to the future research performance of the school.

\section{Key people who have had an impact on IS}

The last section in the analysis and findings for level one (descriptive analysis, as outlined earlier) considers key people who have had an impact on IS at the UTAS. While a range of individuals was identified as having had an impact on IS at the UTAS, only two were mentioned by more than one participant. Professor Chris Keen was the individual mentioned most frequently. He was seen to be responsible for the inception of the School of Information Systems, and acknowledgement was made of his considerable entrepreneurial skills and vision. Reference was also made to his influence on some of the current staff members as their supervisor while they completed their $\mathrm{PhD}$. The role of Professor Arthur Sale was also acknowledged for recognising the need to introduce a more applied course in ICT at the UTAS when he was Head of the Department of Computer 
Science. Vignettes that set out the background and achievements of Professors Keen and Sale are provided below, as representative of those who have made a major contribution to IS in the state.

\section{Vignette-Chris Keen}

Chris Keen had a formative impact on the development of the IS discipline in Tasmania. Keen was with the UTAS for 29 years from 1978 to the end of 2006. He spent much of that time in the Department of Information Science, later Computer Science. In 1996, he became head of that department and was instrumental in the formation of the new School of Information Systems on 1 January 1997. He continued as the head of that school until 2004, and was appointed Professor of Information Systems in 1999.

Keen gained his $\mathrm{PhD}$ in the area of analytical modelling of database systems in 1979, and pursued a teaching and research career that focused on applications of IT in the areas of database systems, simulation, management of IS, business logistics and strategic alignment of ICT. From 1991, he actively developed teaching and research programs in IS.

A key aspect of Keen's career has been a continuing, strong involvement with industry and government agencies and the conscious need to represent and advance the ICT industry in Tasmania. This has taken the form of numerous consultancies, appointments to boards and a range of other joint developments with industry partners. As an example, in 1996 Keen was instrumental in conceptualising, gaining funding for and establishing the Tasmanian Electronic Commerce Centre (TECC). As a joint venture between the UTAS and the Tasmanian government, the TECC provided an ideal portal through which researchers in IS could interact meaningfully with SMEs - albeit on quite different time scales, and always to the mutual benefit of all parties. More recently, Keen has pursued a similar approach through active involvement with the regional development authority, Northern Tasmania Development, especially in support of the tourism industry.

Keen has been active on a number of government and professional boards, including the Information Resource Management Task Force (1992-93), the Intelligent Island Board (2000-03), the Tasmanian IT Industry Council (2001-02) and the Tasmanian Branch of the ACS.

A key aspect of Keen's approach to scholarship has been the need to inform teaching and research through professional activities. His belief is that relevance must always be maintained, together with the pursuit of quality of teaching and learning and rigour in the application of research methodologies.

His main research interests are in the modelling of IS, business logistics and IS. A key objective in the early 1990s was the rapid recruitment of a large number of postgraduate research students to develop a pool of expertise and provide a 
vibrant research culture. One career highlight has been the opportunity to work with highly gifted graduate research students as they complete their candidatures. Keen has successfully co-supervised 15 postgraduate research students.

Between 1990 and 1994, Keen was a member of the executive of the Computer Science Association. This involvement highlighted the need for a peak body to represent IS academia in Australia. Between 1995 and 1999, Keen was active in the establishment of the Australian Council of Professors and Heads of Information Systems (ACPHIS). He saw the need for such a group to work towards binding the IS community in Australia, and to provide a national voice for the discipline.

In late 2006, Keen left academia to undertaken full-time consultancy with industry and, paradoxically, to be free to engage more actively in IS research and development.

\section{Vignette-Arthur Sale}

Arthur Sale started working in the ICT field in 1963 as one of the hardest of hard computer scientists: an electronics engineer designing a new computer system at Philips NV in the Netherlands. He later worked at the University of Natal in South Africa before emigrating to Australia to become a senior lecturer at the University of Sydney. He later took up the Foundation Chair of Information Science at the University of Tasmania, where he has been ever since-apart from study leave and international research travel.

In 1988-90, he was elected chair of the University's Professorial Board. From 1993-99, he held the position of Pro-Vice-Chancellor (Information Systems) and was a member of the Vice-Chancellor's Executive, including spells as Acting Vice-Chancellor.

At the time of writing, Sale holds a position as Professor of Computing (Research) and is an Emeritus Professor of the UTAS. He holds the unusual record of having given nine graduation addresses. Until March 2007, he was the School of Computing's Graduate Research Coordinator, responsible for all $\mathrm{PhD}$ candidates.

The Department of Information Science that he founded in 1974 diversified over time, and with his encouragement began teaching IS topics under the initial leadership of Mike Rees, and later Chris Keen. After Sale left to become Pro-Vice-Chancellor, the department divided into two computer science and IS schools.

Sale graduated with a bachelor degree in electronics engineering cum laude in 1961, followed by a very early PhD in computer science in 1969. His thesis title was 'Accelerating the arithmetic of binary digital computers' and dealt mainly with problems of fast binary divisions. He has been known to describe himself 
as a 'living dinosaur' because he wrote several programs for his research on a vacuum-tube computer.

In his research, Sale has spanned the range of ICT activities, writing and researching on topics from silicon-chip designs through to the impact of new technology on society, the importance of open-access repositories to universities globally and scientometric measures of research impact.

On his arrival in Australia, Sale joined the ACS and was quickly drafted into the NSW Branch Executive. When he moved to Tasmania, he acted to initiate the Tasmanian branch and was its first vice-chair. He has continued to be active in the ACS, serving as Tasmanian Chair, member of the National Council and National Vice-President. Sale holds all three ACS badges for service to the society. He was Tasmania's first Fellow of the ACS and is also a Fellow of Engineers Australia.

His main research interests at present include bioinformatics and algorithms for carrying out operations on DNA and proteins, open access and the measurement of quality in research, and mobile computing and human interface technology, particularly in usability and impact. Sale presently supervises four $\mathrm{PhD}$ candidates, spanning these issues as well as visualisation of fish schools using sonar, and parallelisation optimisations.

His awards include the Australian National Committee on Computation and Automatic Control (ANCCAC) Prize for the best paper published on ICT in Australia in 2001-on the impact of wireless networking on broadband access - and the Vice-Chancellor's Award for Outstanding Community Achievement (Tasmania, 2006).

\section{Others}

Other individuals were mentioned by participants. Jeremy Firth and Stephen Haynes from the Tasmanian public sector were described as strong advocates for an IS program at the UTAS in the 1990s. Reference was also made to the contribution made by Cathy Urquhart and her role in the development of the first IS course at the UTAS, and John Lamp for his development of a web-based service for the Australasian and international IS community. Bob Godfrey's role within the ACS and his involvement with the development of IS curricula were also acknowledged. More recent contributions that were recognised included Paul Turner's strong engagement with industry, Peter Marshall's focus on research and Roy Barkas's role within Logica CMG in hiring IS graduates and providing assistance with research.

This section has presented the findings for level one, providing a descriptive examination of IS at the UTAS, drawing on qualitative and quantitative sources. The next section sets out the analysis and findings for level two of this study, and examines whether an inverse relationship could be identified between the 
impact of local contingencies on the IS discipline and the degree of professionalism within the UTAS setting.

\section{Analysis and findings: level two}

Figure 3.2 of the theoretical framework guiding the study-and presented in an earlier chapter - postulated an inverse relationship between the impact of local contingencies on the IS discipline and its degree of professionalism.

The impact of local contingencies at the School of Information Systems at the UTAS was evaluated by categorising the level-one data relating to research and teaching issues, including the variation in both by centre, into high, medium or low impact. Non-local factors were omitted. Where the categorisation by the second researcher differed, discussion took place until agreement was reached. Qualitative and quantitative data were considered, where relevant. This analysis is presented in Table 8.4.

Overall, it can be seen from Table 8.4 that local contingencies had a low to medium impact on curriculum and teaching issues, while they had a high to medium impact on research issues. Research was influenced particularly by local factors, with no issues recorded in the low range and few in the medium range. An analysis of the extent of professionalism of the IS discipline at the UTAS follows.

The degree of professionalism for research and teaching issues at the School of Information Systems in Hobart was also evaluated using the level-one data, employing the same method used for the evaluation of the impact of local contingencies. Professionalism requires high task certainty, routinisation of activities and a clear division of labour. The analysis is set out in Table 8.5. 
Table 8.4 Classification of the impact of local contingencies on research and curriculum/teaching

\begin{tabular}{|c|c|c|c|}
\hline Area & High & Medium & Low \\
\hline $\begin{array}{l}\text { IS curriculum and } \\
\text { teaching issues }\end{array}$ & $\begin{array}{l}\text { Three-campus delivery of IS } \\
\text { in Tasmania influenced by } \\
\text { politicians; } \\
\text { Oracle taught because of its } \\
\text { use in the Tasmanian } \\
\text { government, the major } \\
\text { employer of IS graduates }\end{array}$ & $\begin{array}{l}\text { Funding pressures make } \\
\text { adjusting staff profile to } \\
\text { student demand difficult; } \\
\text { Role of course advisory } \\
\text { committees, particularly for } \\
\text { MIS degree; } \\
\text { Increased use of } \\
\text { video-conferencing, WebCT } \\
\text { for teaching at non-Hobart } \\
\text { campuses; } \\
\text { Some variation in delivery to } \\
\text { Shanghai and Fuzhou. }\end{array}$ & $\begin{array}{l}\text { Teaching focus does not } \\
\text { vary by campus; } \\
\text { Moderation undertaken } \\
\text { across multiple campuses; } \\
\text { Team marking across } \\
\text { campuses; } \\
\text { Single points of course } \\
\text { development for each unit; } \\
\text { Very similar unit content } \\
\text { across all centres; } \\
\text { Teaching fairly centralised } \\
\text { in Hobart. }\end{array}$ \\
\hline IS research issues & $\begin{array}{l}\text { Research not controlled } \\
\text { centrally; } \\
\text { Few common topics; } \\
\text { Early emphasis on electronic } \\
\text { commerce (EC), influenced } \\
\text { by Tasmanian EC Centre; } \\
\text { Some research involvement } \\
\text { in Telstra Broadband Lab, } \\
\text { enabled through funding } \\
\text { from Senator Harradine; } \\
\text { IT sometimes dealt with } \\
\text { locally by accountants; } \\
\text { greater use of consultants } \\
\text { and outsourcing; } \\
\text { Small size of state means } \\
\text { easy access to supportive } \\
\text { government agencies; } \\
\text { Limited large private sector } \\
\text { and manufacturing } \\
\text { organisations has } \\
\text { emphasised SME and } \\
\text { government research; } \\
\text { Limited research culture; } \\
\text { Appointment of Woolworths } \\
\text { Chair in IS associated with } \\
\text { political pressure on state } \\
\text { government; } \\
\text { Limited PhD supervisors; } \\
\text { No research conducted in } \\
\text { school centres outside } \\
\text { Tasmania. }\end{array}$ & $\begin{array}{l}\text { Common interest in } \\
\text { electronic commerce in } \\
\text { previous years; diverging } \\
\text { justification for this } \\
\text { provided; } \\
\text { Emphasis on interpretive } \\
\text { methods, but positivist } \\
\text { approaches used and } \\
\text { taught; } \\
\text { Faculty influence on } \\
\text { research topics and } \\
\text { structure. }\end{array}$ & \\
\hline
\end{tabular}

Table 8.5 suggests that IS curriculum and teaching activities had a high to medium level of professionalism at the UTAS, while research activities had a low to medium degree of professionalism. 
Table 8.5 Classification of features of IS research and curriculum and teaching at the UTAS by degree of professionalism

\begin{tabular}{|c|c|c|c|}
\hline Area & High & Medium & Low \\
\hline $\begin{array}{l}\text { IS curriculum and } \\
\text { teaching issues }\end{array}$ & $\begin{array}{l}\text { Relatively centralised } \\
\text { location of staff in Hobart } \\
\text { aids task certainty through } \\
\text { opportunities for } \\
\text { communication; } \\
\text { Moderation of teaching } \\
\text { across campuses; } \\
\text { Similar teaching content } \\
\text { across campuses; } \\
\text { High-quality flexible online } \\
\text { support is an example of } \\
\text { clear division of labour in } \\
\text { this area; } \\
\text { Widespread use of } \\
\text { workshops and case studies } \\
\text { in teaching; } \\
\text { Range of mechanisms exists } \\
\text { to promote good teaching; } \\
\text { Sequential delivery style } \\
\text { used to develop student } \\
\text { responsibility from Years } \\
1 \text {-3; } \\
\text { Focus on management and } \\
\text { strategy in teaching; } \\
\text { Four major teaching themes } \\
\text { identified. }\end{array}$ & $\begin{array}{l}\text { Staff performance } \\
\text { management scheme sets } \\
\text { teaching targets; } \\
\text { Little emphasis on service } \\
\text { teaching means greater } \\
\text { routinisation across degrees; } \\
\text { Oracle certification is an } \\
\text { example of high task } \\
\text { certainty. }\end{array}$ & \\
\hline IS research issues & & $\begin{array}{l}\text { Some emphasis on } \\
\text { qualitative research } \\
\text { methods; } \\
\text { Perceived fewer incentives } \\
\text { for research than for } \\
\text { teaching; } \\
\text { Some incentives provided } \\
\text { by faculty/university to do } \\
\text { research. } \\
\text { Some emphasis on SME and } \\
\text { government research; } \\
\text { New focus on IT } \\
\text { governance, business } \\
\text { process management; } \\
\text { Majority of staff expected } \\
\text { to undertake research. } \\
\end{array}$ & $\begin{array}{l}\text { Research program not } \\
\text { controlled centrally; } \\
\text { Few common topics; } \\
\text { Research culture hard to } \\
\text { sustain, detracting from } \\
\text { routinisation of research; } \\
\text { Perceived lack of recognition } \\
\text { for productive research } \\
\text { staff; } \\
\text { Limited history of attracting } \\
\text { ARC funds; } \\
\text { Less attendance at } \\
\text { conferences than in past; } \\
\text { Perceived need to focus on } \\
\text { fewer research areas; } \\
\text { Limited quality journal } \\
\text { publications reduces task } \\
\text { certainty for publishing in } \\
\text { these journals; } \\
\text { High teaching loads leave } \\
\text { little time to routinise } \\
\text { research. }\end{array}$ \\
\hline
\end{tabular}

An examination of IS at the UTAS in 2007 and beyond will be presented next, before the conclusions of this study are considered. 


\section{IS at the UTAS in 2007 and beyond}

In the past, the discipline of IS needed to be flexible in the face of change. This characteristic, as applied to the UTAS, is considered in this section. The position of teaching and research for the School of Information Systems is reviewed in the first subsection, as of mid-2007, as provided by a senior academic from the school. As indicated earlier, the structural position of the school changed from the beginning of 2008, when it merged with the School of Computing and transferred from the Faculty of Business to the Faculty of Science, Technology and Engineering. In a subsection that follows, two senior academics from the UTAS reflect on the future structural position of IS, from different perspectives.

\section{IS research and teaching at the UTAS in mid-2007}

Acknowledgement is made to Professor Peter Marshall, who provided the following updated information on research and teaching at the School of Information Systems in June 2007.

Due in large part to a number of research grants, the school had more than 20 $\mathrm{PhD}$ students as of June 2007. The PhD students have been welcomed to play a strong and inclusive role in the school, contributing to a vibrant research ambience. Regular research seminars have been held, as well as visits by eminent researchers from interstate and outside Australia. The vigorous research activity and research culture in the school has been due largely to the efforts of Associate Professor Paul Turner, as much of the research in the school has been directed and led by him. Since 2001, he has been involved directly in raising more than $\$ 4.3$ million in research grants and consultancies. In working with his $\mathrm{PhD}$ students, Turner published more than 90 peer-reviewed journal articles, book chapters and conference papers.

There were three key research foci in the School of Information Systems at the UTAS as of 2007. First, there was a group led by Professor Marshall that focused on IS strategy and business process analysis, modelling and improvement in SMEs. Since 2005, this group, consisting of three academic staff members including Marshall, has carried out two action-research projects into IS strategy formulation in local SMEs. Two business-process experts from the Queensland University of Technology (QUT) have helped the group with this research.

Second, there was the e-health group led by Associate Professor Paul Turner. This group conducted research at basic, applied and strategic levels across acute, primary and aged and community care. The group had eight active researchers engaged in more than 10 funded research projects that had a combined value of more than \$3 million. Since 2004, the group has published more than 44 peer-reviewed papers, as well as producing a number of reports, advisories and commentaries. The group also engaged in consultancy to government and industry. 
Finally, there was the e-Forensics, Security and Business Logistics Group, also led by Turner. This group also had eight active researchers engaged in applied and strategic-level research covering the following areas:

- e-forensics (digital evidence acquisition related to criminal, illegal or inappropriate online behaviour)

- computer security (including investigations of cyber-terrorism and threats to critical infrastructure)

- Internet fraud

- organisational protection methods

- business logistics (tracking and traceability across entire cold-chain supply chains deploying radio frequency identification technologies (RFIDs) and other technologies with a focus on the perishable seafood export industry).

The e-Forensics, Security and Business Logistics Group has produced more than 27 peer-reviewed publications in recent years and has been involved in research collaborations with a value of more than $\$ 450,000$.

The teaching program in the School of Information Systems at the UTAS continued to be similar to a number of IS programs across Australia and covered systems analysis, system development methodologies, project management, information management and IS strategic planning.

From information provided on the school's web site, by mid-2007, 15 staff members were employed either full-time or part-time, and based in the School of Information Systems. Of these, nine were academic staff members, while another two undertook research positions. The school continued to have three administrative officers, including those who worked part-time, and one technical officer was employed under a service-level agreement with the university. Of these staff members, all were based in Hobart except for two academic staff members, who were based in Launceston.

In the next section, two senior academics who have been associated with IS at the UTAS at different times reflect on changes to the structural placement of IS, from different perspectives.

\section{The structural placement of IS with computing: perspective 1}

\section{Arthur Sale, Emeritus Professor of Computer Science, former Pro-Vice-Chancellor}

This short statement expresses a personal view of the structural placement of IS (and computer science) in the UTAS. The views might be of relevance to other universities. This contributor has had no input to university decisions since 1999. 


\section{Context}

The context is that IS and computer science have been taught by two 'schools' (or departments) in the UTAS. Both schools have been under financial stress from loss of undergraduate student numbers, especially of Australian students, and low research output. The stress was perhaps higher for IS than for computer science, since the latter was somewhat larger, had attracted a large international intake and was perhaps slightly more research active. The two schools are named (eponymously) Information Systems in the Faculty of Business and Computing in the Faculty of Science, Engineering and Technology. Both had their genesis in a single school. Senior executives do not believe that there are any distinguishing differences between the disciplines.

In March 2007, the vice-chancellor and the senior executive consisting of all the deputy and pro-vice-chancellors and the deans invited the two schools to come up with a plan for 'marriage' before the 2008 budget was drawn up. This gave urgency to the question of where the discipline of IS fits in the UTAS.

The background to this 'request' was that both schools were in trouble with funding related to outputs; neither school had been able to satisfactorily differentiate its offerings from the other to Tasmanian school-leavers despite enormous effort, marketing had been unsuccessful in leading to growth and the university was unconvinced that the 'corner had been turned'. The two schools were not seen as worth saving as separate entities for their research output or for their community contribution. These are all arguable assessments, but were nevertheless persuasive arguments to university management.

\section{Views}

Personally, I view IS as having established itself completely as a sub-discipline within the field of ICT. There are, however, many other sub-disciplines within this field, such as computer architecture, networking technologies, software engineering, theoretical computer science, mobile computing, Internet technologies, robotics, and so on. They form an overlapping and continuous spectrum of ICT application.

None have any existence without the pervasive impact of computer artefacts. As a former chair of a unified school but without influence, I regretted the break-up into two entities and I welcomed a possibility of reuniting them. This might not be so obvious to schools of IS that were founded independently, but I believe that the computer artefact is at the core of all these sub-disciplines, and unnecessary fragmentation serves no one.

In larger universities, the continued existence of IS and computer science schools might be retained, especially as IS often established itself in a separate faculty. If an amalgamated school would be too large for good management, independent existence is a good option. 
Even then, however, IS is on difficult ground, as it is often moving out of its obsolescent business background into education, medicine, architecture and even science, as the discipline that deals with computer applications. This brings it into direct conflict with computer science, which has never given up this ground. The pressure will be on to bring the ICT disciplines closer together.

In smaller universities, such as the UTAS, the outcome is likely to be a single school, which has some advantages of greater coherence, though it might come with angst and turmoil in the short term.

In fact, when I look at the research output of the School of Computing at the UTAS, perhaps 50 per cent of the papers could be classified as 'information research' and are capable of being done in a large, competent IS school. The remainder consists of artificial intelligence, image processing, robotics and a few other theoretical computer science matters such as graph theory, bioinformatics and parallelism. In IS at the UTAS, its involvement in medical informatics and in ICT forensics could fit equally well in computer science.

Perhaps we all need to take a step back and decide what matters to us and to society, and whether the decades-old split between computer applications and infrastructure deserves to be mended. After all, the ACS has never ceased to encompass both.

\section{The structural placement of IS with computing: perspective 2}

\section{Peter Marshall, Head of School of Information Systems and Woolworth's Chair of Information Technology and Systems}

The following statement is written from my perspective as Woolworths Chair of Information Technology and Systems at the UTAS, having joined the School of Information Systems in June 2004. In December 2004, I became Head of School, and have continued in that role until the present day.

The research program in the School of Information Systems at the UTAS has had a strong emphasis on the identification, design, planning and management of IS in organisations. The context of the use of IT is taken to be critical to, and inseparable from, its effective utilisation. The teaching program is similar to other IS programs across Australia.

\section{Skills and knowledge required by ICT professionals}

The skills and knowledge taught in an IS program, particularly those related to the planning and management of IS, are, I believe, now the dominant skills and knowledge required by ICT professionals in Australia. 
Courses that have a heavy emphasis on software engineering and computer science are now, I believe, suitable only for the few specialists who will be required in the technical domains of specialist software engineering, robotics, computer-game programming and similar areas. There have been some highly significant trends in ICT in the past 30 years that have apparently gone unnoticed by the more technically enthusiastic ICT academics. These include the considerable trend towards the use of ICT application packages including enterprise resource planning (ERP) systems, rather than the building of customised applications in every organisation, as was the case in the 1960s and 1970s. These trends also include the increasing use of outsourcing and offshoring, which has seen applications development focused in large multinationals, and in firms in India and other relatively low-wage countries. Another development that I believe will, again, reduce the need for technical ICT skills is the increasing availability and use of application service providers. These trends and developments, together with the obvious fact that ICT is now much more reliable than it was 20 to 30 years ago, means that, in my opinion, the disciplines of computer science and software engineering will decline in relevance and importance to the bulk of ICT students relative to that of IS. Of course, it will take some time for enrolments in computer science and software engineering to decline when compared with IS, since school students are less aware of the impact of these developments.

\section{Merger of the Schools of Computing and Information Systems}

Faced with declining enrolments in the Schools of Information Systems and Computing, the Vice-Chancellor of the UTAS urged both schools to merge. A working party on this issue formed from key individuals in both schools accepted the idea of a merged or joint school. The new combined school resides in the Faculty of Science, Engineering and Technology.

In the merger of the two schools, the problem of declining enrolments was considered. Generally, however, at present, the problem with declining enrolments in IS and computing throughout much of the world remains not well understood and awaiting resolution. Synergies in teaching and learning in the new merged school at the UTAS, and in new course design and implementation in particular, will be utilised to address declining enrolments. To assist with such endeavours, a market research study will be undertaken into the perceptions and opinions of potential students regarding ICT courses, and into the skills and knowledge needs of ICT professionals in contemporary business and government.

This background work will provide a firm basis on which to plan and design new courses that are attractive to potential students and relevant to the needs of business and government in Tasmania. This study will also provide a firm 
basis for planning marketing initiatives for ICT courses for the future at the UTAS.

After 11 years of operation as a separate school within the Faculty of Business, IS returned to the Faculty of Science, Engineering and Technology in 2008, in a combined structural relationship with computing. Although the IS research output in mid-2007 was reported as being healthy, the erosion in student numbers for IS and computing was pointed to as the driver behind the resumed co-location of the two disciplines at the UTAS. Two different perspectives on the relationship between computing and IS have been presented.

\section{Conclusions}

This final section reviews the findings, and presents the study's limitations and suggestions for future research.

In the descriptive analysis of the School of Information Systems at the UTAS, the extent to which IS was impacted on by local factors, whether it was perceived to be a separate field at the university, the distinctive characteristics of its curriculum and research and the key people who had an impact on IS at the UTAS were considered. An analysis was then undertaken of the perceived degree of impact of local contingencies and the degree of professionalism-for IS teaching and research at the UTAS.

The level-two analysis suggests that while local contingencies had a low to medium impact on curriculum and teaching, they had a high to medium impact on research issues. There were, however, indications that the reverse was the case for the degree of professionalism, in that curriculum and teaching issues had a high level of professionalism while research activities were assessed as low to medium. These findings for research issues are consistent with the view of IS as a fragmented adhocracy, as explained in the framework chapter earlier in this volume. The different findings for curriculum and teaching issues have not, it is believed, been identified before for IS, and make a contribution to research on the development of this discipline.

The level-two findings are consistent with the postulation from the theoretical framework that an inverse relationship exists between the impact of local contingencies on a discipline and its degree of professionalism. As the findings were derived from a single case study, however, the inverse relationship found is best confirmed by case studies conducted in other areas of Australia and elsewhere. Moreover, if the findings are confirmed in different regions using different methods of analysis, this characteristic will act to strengthen the findings.

Additional planned future work is to examine the remainder of the theoretical framework developed for the study through a cross-case analysis of how the components of the IS discipline developed over time. It is possible that the 
framework might need modification as a result of its application to further cases. Once these level-three findings are known, comparison can be made with research conducted in Europe and North America to see if the common findings extend to Australia at least six years later.

The degree of change experienced in the IS discipline is demonstrated by this case study from Tasmania. This chapter has reported that teaching and research into IS at the single university in the state resumed in a science-based faculty, in conjunction with computing, after 11 years in a separate school in a business faculty. Opportunities exist for future research that examines the impact of co-location of IS with computing at the UTAS on student enrolments, teaching and research.

\section{Acknowledgements}

Professors Chris Keen, Peter Marshall and Arthur Sale are thanked for their generous contribution to this chapter.

\section{Select bibliography}

Avgerou, C., Siemer, J. and Bjørn-Andersen, N. 1999, 'The academic field of information systems in Europe', European Journal of Information Systems, vol. 8, no. 2, pp. 136-53.

Dixon-Woods, M., Agarwal, S., Jones, D., Young, B. and Sutton, A. 2005, 'Synthesising qualitative and quantitative evidence: a review of possible methods', Journal of Health Services Research \& Policy, vol. 10, no. 1, pp. 45-53.

Information Resources Management Association (IRMA) 1996, The Information Resources Management Curriculum Model: An international curriculum model for a 4 year undergraduate program in IRM, A joint activity of IRMA and DAMA, IRMA, Harrisburg, Pa.

Longnecker, H., Clark, J., Couger, D., Feinstein, D. and Clark, J. 1995, IS'95: Model curriculum and guidelines for undergraduate degree programs in information, A joint activity of DPMA, ACM, ICIS and AIS, School of CIS, University of South Alabama, Mobile, Ala.

Ridley, G. 2006, 'Characterising information systems in Australia: a theoretical framework', Australasian Journal of Information Systems, vol. 14, no. 1, pp. $141-62$.

University of Tasmania 2007, Welcome by the Vice-Chancellor, University of Tasmania, viewed 15 June 2007, $<$ http://www.utas.edu.au/uni/welcome.html $>$ 
Watson, H. J., Taylor, K. P., Higgins, G., Kadlec, C. and Meeks, M. 1999, 'Leaders assess the current state of the IS academic discipline', Communications of the AIS, vol. 2, no. 2.

Whitley, R. 1984, The Intellectual and Social Organization of the Sciences, Clarendon Press, Oxford, UK.

\section{Appendix 8.1}

Table A8. I Programs offered at the School of Information Systems, University of Tasmania, as of the end of 2005 and of mid-2007

\begin{tabular}{|c|c|}
\hline 2005 & 2007 \\
\hline Undergraduate & Undergraduate \\
\hline BIS & $\mathrm{BIS}^{\mathrm{a}}$ \\
\hline BIS/BBus & BIS/BBus \\
\hline BIS (Hons) & BIS (Hons) \\
\hline BIS/BMusic & BIS/BMusic \\
\hline BIS/BTeaching & BIS/BTeaching \\
\hline BIS/BLaws & BIS/BLaws \\
\hline BFA/BIS & BFA/BIS \\
\hline BIS/DiplT ${ }^{c}$ & BIS/DiplT ${ }^{c}$ \\
\hline Postgraduate course-work & Postgraduate course-work \\
\hline \multirow[t]{3}{*}{ MIS } & MIS \\
\hline & MEB $^{\mathrm{d}}$ \\
\hline & MEB (Specialisation) ${ }^{d}$ \\
\hline GDIS & GDIS \\
\hline GDInfoMgt $^{b}$ & GDInfoMgt $^{\mathrm{b}}$ \\
\hline GCIS & GCIS \\
\hline RHD & RHD \\
\hline $\mathrm{PhD}$ & $\mathrm{PhD}$ \\
\hline
\end{tabular}

